\title{
Cardiac $\beta$-adrenoceptor expression is markedly depressed in Ossabaw swine model of cardiometabolic risk
}

This article was published in the following Dove Press journal:

International Journal of General Medicine

23 June 2011

Number of times this article has been viewed

\section{U Deniz Dincer}

Department of Pharmacology, Ufuk University School of Medicine, Ankara, Turkey
Correspondence: U Deniz Dincer Department of Pharmacology, Ufuk University School of Medicine, Farmakoloji ABD, A Blok No: 322,

Mevlana Bulvari, No: 86-88, 06520

Balgat, Ankara, Turkey

Tel +903I2 2044156

Fax +90312 2044055

Email uddincer@ufuk.edu.tr
Abstract: Ossabaw swine have a "thrifty genotype" and consumption of excess calories induces many classical components of the metabolic syndrome, including obesity, insulin resistance, impaired glucose tolerance, dyslipidemia, hyperleptinemia, and hypertension. Earlier studies indicate that the metabolic syndrome is associated with diminished cardiac function; however, to what degree this impairment is associated with alterations in myocardial $\beta_{1}$ - and $\beta_{2}$-adrenoceptor (AR) expression has not been fully elucidated. Accordingly, the present study was designed to investigate the effects of the metabolic syndrome on cardiac $\beta_{1}$ - and $\beta_{2}$-AR expression. Studies were conducted on left ventricular tissue samples obtained from control lean and chronically (50 weeks) high-fat-fed obese animals. Chronic feeding significantly increased fasting plasma insulin, total cholesterol, triglycerides, blood glucose, systolic and diastolic blood pressure, and heart rate. Real-time polymerase chain reaction revealed no significant alterations in cardiac $\beta_{1}$ - and $\beta_{2}$-AR mRNA expression. In contrast, Western blot analysis revealed a significant decrease in ventricular $\beta_{1}$ - and $\beta_{2}$-AR protein expression. This is the first report in a novel large animal model that induction of metabolic syndrome is accompanied by a significant reduction in cardiac $\beta_{1}$ - and $\beta_{2}$-AR protein expression that could contribute to impaired cardiac function.

Keywords: hypertension, metabolic syndrome, $\beta$-AR, impaired cardiac function

\section{Introduction}

With the increasing burden of childhood obesity, the prevalence of metabolic syndrome in children still varies widely. ${ }^{1}$ However, using Adult Treatment Panel (ATP) III and World Health Organization criteria, a school-based study on metabolic syndrome has reported prevalence at $4.2 \%$ and $8.4 \%$, respectively. ${ }^{1}$ Importantly, pediatric metabolic syndrome needs to be tracked very carefully from childhood to adulthood to prevent cardiometabolic risk. ${ }^{2}$ Metabolic syndrome is known to be associated with higher cardiovascular mortality and morbidity, which is referred to as "cardiometabolic risk" in the clinics. ${ }^{3}$ Despite genetic and environmental factors, the key elements of metabolic syndrome are obesity, impaired glucose tolerance, insulin resistance, increased lowdensity lipoprotein:high-density lipoprotein ratio, increased fasting and postprandial triglyceride levels, and hypertension. ${ }^{4}$ Specifically, centrally distributed adiposity in obesity strongly correlates with adult cardiometabolic risk. ${ }^{3}$

This multifaceted syndrome can result in a variety of cardiac and hemodynamic alterations that ultimately result in development of congestive heart failure., ${ }^{2,3}$ The mechanisms responsible for these disturbances are mainly multifactorial but could be related to a hyperdynamic circulatory state, which is characterized by increased 
blood pressure, total blood volume, cardiac output, and tissue metabolic demand. ${ }^{5-7}$ Basal catecholamine level generally increases, a finding supported by many studies. ${ }^{6,8,9}$ Increased sympathetic system activity could stimulate G-proteincoupled $\beta$-adrenoceptors (ARs), elevating intracellular cyclic adenosine monophosphate (cAMP), thereby activating protein kinase A (PKA) or calcium calmoduline kinase II (CaMKII). ${ }^{10-12}$ The duration of the disease is the key factor that attenuates $\beta$-AR-mediated cardiac responses and underlying mechanisms.

Determining the effects of metabolic syndrome on cardiac $\beta$-AR expression seems to be one of the novel therapeutic strategies against obesity-induced cardiometabolic risk. The author of this study determined hemodynamic parameters such as systolic, diastolic, and mean arterial blood pressures as well as heart rate. Real-time polymerase chain reaction (PCR) and Western blot analysis were used to assess mRNA and protein expressions in the left ventricles obtained from control and chronically (50 weeks) high-fat-fed animals. For that purpose, I selected obese Ossabaw swine, which are one of the novel large animals and the most similar model to human metabolic syndrome.

\section{Methods}

\section{High-fat diet}

This investigation was approved by the Indiana University School of Medicine Institutional Animal Care and Use Committee and was conducted in accordance with the Guide for the Care and Use of Laboratory Animals. Ossabaw pigs were fed either a normal diet (Teklad, $\sim 13 \%$ calories from fat; $n=7)$ or a high-fat diet $(\sim 6 \%$ of calories from fat; $\mathrm{n}=9)$. The high-fat diet was administered in the morning and afternoon for $\sim 50$ weeks. The pigs were maintained on this diet throughout the experimental protocol.

\section{Analytical procedures}

Plasma supernatant was collected and stored at $-80^{\circ} \mathrm{C}$.

\section{Isolation and quantitation of total RNA}

Left ventricles obtained from control and high-fat-fed Ossabaw swine. They were placed in liquid $\mathrm{N}_{2}$ and stored at $-80^{\circ} \mathrm{C}$. Total RNA was extracted according to manufacturer's instructions (SV Total RNA Isolation System, Promega Corp, Fitchburg, WI). At the end of the isolation, RNA samples were dissolved in nuclease-free water ( $\mathrm{pH} 7.5)$. The total RNA quantity and quality were determined using the Experion ${ }^{\mathrm{TM}}$ Semi-automated Electrophoresis System (Bio-Rad Laboratories, Inc, Hercules,
CA). In the Experion priming station, the microfluidic-based LabChip sample wells (RNA StdSens Chips, Experion, BioRad) were filled with a polymer-sieving matrix containing a fluorescent dye and $1 \mu \mathrm{L}$ of denatured total RNA. The concentration of total RNA was determined by using the ratio of the sample RNA area to the Experion RNA ladder area. RNA samples with distinct $18 \mathrm{~S}$ and $28 \mathrm{~S}$ ribosomal RNA fragments in the electropherogram were used to assess RNA quality.

\section{Preparation of first-strand cDNA via reverse transcriptase reactions}

RNA samples were used as templates for synthesis of first-strand cDNAs as described previously. Briefly, $1 \mu \mathrm{L}$ of oligo(dT)15 primer (Promega) was added to equivalent amounts of total RNA obtained from left ventricles isolated from control $(n=5)$ and chronically high-fat-fed $(n=5)$ pigs. The mixtures were then placed into a thermocycler (My Cycler ${ }^{\mathrm{TM}}$, Bio-Rad) and held at $70^{\circ} \mathrm{C}$ for 5 minutes. The samples were then transferred into an ice bath for 5 minutes to permit selective binding of the oligo(dT) 15 to the $\operatorname{poly}(\mathrm{A})$ tail of the mRNA. First-strand cDNA was then synthesized with an ImProm-II Reverse Transcriptase kit (Promega). ${ }^{8,17}$

\section{Amplification of cDNA}

Real-time PCR reactions were performed for $\beta_{1}-, \beta_{2}-\mathrm{ARs}$, and $\beta$-actin in triplicate with a custom-designed SYBR ${ }^{\circledR}$ Green mix (2.4 $\mu \mathrm{L}$ of $25 \mathrm{mM} \mathrm{MgCl}_{2}, 5 \mu \mathrm{L}$ of 1:10,000 dilution SYBR Green I, Molecular Probes, Inc, Eugene, OR) and $5 \mu \mathrm{L}$ of $1 \mathrm{nM}$ fluorescein calibration dye $(1 \mathrm{mM} / \mathrm{L}$ in dimethyl sulfoxide, Bio-Rad) in $50 \mu \mathrm{L}$ of total reaction using Taq DNA polymerase (Promega). ${ }^{8,17}$ Primers were designed using the Genomatix Software Suite program (Müchen, Germany) based on sequences published in the National Center for Biotechnology Information GenBank database. ${ }^{18}$ Gene-specific primers were used: for $\beta_{1}$-ARs, sense 5'-GACCGAAAGCAGGTGAACTC-3' and antisense 5'-CTCCCATCCCTTCCCTAGTC-3' (242 bp product; accession number AF042454); for $\beta_{2}$-ARs, sense 5'-GCCATCGACTGCTATCACAA-3' and antisense 5'-GGTTTGGGGAGTGGAATCTT-3' (193 bp product; accession number U53185); for $\beta$-actin, primers were designed based on published sequences in the GenBank database (sense 5'-ACGTGGACATCAGGAAGGAC-3' and antisense 5'-ACATCTGCTGGAAGGTGGAC-3'; accession number U07786).

Amplification was carried out with iCycler iQ multicolor real-time PCR detection system (Bio-Rad) as follows: 
45 -second denaturation $\left(94^{\circ} \mathrm{C}\right)$ followed by 45 -second annealing and 1-minute extension $\left(72^{\circ} \mathrm{C}\right)$, repeated for a total of 40 cycles. $\beta$-actin was amplified in each set of PCR reactions and served as an internal reference during quantitation to correct for operator and/or experimental variations. The data were analyzed in triplicate using the $2^{-\Delta \Delta \mathrm{Ct}}$ equation. $8,17,19$

$\Delta \Delta \mathrm{C}_{\mathrm{t}}=\left(\mathrm{C}_{\mathrm{t} \beta \text {-ARs }}-\mathrm{C}_{\mathrm{t} \beta \text {-actin }}\right)_{\text {high-fat diet }}-\left(\mathrm{C}_{\mathrm{t} \beta \text {-ARs }}-\mathrm{C}_{\mathrm{t} \beta \text {-actin }}\right)_{\text {control }}$

The mean threshold cycle $\left(\mathrm{C}_{\mathrm{t}}\right)$ values for both the target ( $\beta_{1}$ - and $\beta_{2}$-ARs) and internal control ( $\beta$-actin) genes were determined in each sample.

\section{Western blot analysis of $\beta_{1}$ - and $\beta_{2}-A R$ proteins}

Left ventricles from control $(n=5)$ and high-fat-fed $(n=5)$ Ossabaw swine were isolated and placed in liquid nitrogen and stored at $-80^{\circ} \mathrm{C}$. Ventricles were homogenized in $150 \mu \mathrm{L}$ of buffer (50 mM Tris- $\mathrm{HCl}$ [pH 7.4], $150 \mathrm{mM} \mathrm{NaCl}$, 1\% Triton X-100 [Sigma-Aldrich, Inc, St Louis, MI], 0.1\% SDS [sodium dodecyl sulphate], $1 \mathrm{mM}$ EDTA [ethylene diamine tetraacetic acid], $1 \mathrm{mM}$ EGTA [ethylene glycol-bis ( $\beta$-aminoethylether)-N,N, $\mathrm{N}^{\prime}, \mathrm{N}^{\prime}$-tetraacetic acid], $10 \mu \mathrm{g} / \mathrm{mL}$ aprotinin, $10 \mu \mathrm{g} / \mathrm{mL}$ leupeptin, $10 \mu \mathrm{g} / \mathrm{mL}$ pepstatin, $5: 1000$ phenylmethylsulfonyl fluoride [200 nM], 5:1000 Na3VO4 [200 nM], and 5:1000 NaF [200 nM]). The homogenates were centrifuged at $45,000 \mathrm{rpm}$ for 30 minutes at $4^{\circ} \mathrm{C}$. The supernatants were collected and used for analysis. Protein quantity and quality were determined using the Experion Semi-automated Electrophoresis System. Basically, $4 \mu \mathrm{L}$ of denatured protein for each sample was loaded into a Pro 260 chip (Experion, Bio-Rad). Equivalent amounts of protein were separated by gel electrophoresis (10\% Tris$\mathrm{HCl}$ Criterion Precast Gel, Bio-Rad). Proteins were transferred onto nitrocellulose membrane $(0.2 \mu \mathrm{m}$, Schleicher and Schuell, London, England, UK) by semidry electroblotting (Trans Blot SD, Bio-Rad) at $15 \mathrm{~V}$ for 1 hour. The nitrocellulose membrane was soaked in $10 \mathrm{mM}$ Tris- $\mathrm{HCl}$ containing 5\% nonfat dry milk (Bio-Rad) and $0.7 \%$ polyoxyethylene-sorbitan monolaurate (Tween ${ }^{\circledR} 20$, Promega), $\mathrm{pH}=7.2$, overnight at $4^{\circ} \mathrm{C}$ to block nonspecific sites. The membranes were then incubated with the $\beta_{1}$ - and $\beta_{2}$-AR purified polyclonal antibodies (1:300 dilution in Trisbuffered saline [TBS] with 5\% nonfat dry milk and $0.1 \%$ Tween 20; Santa Cruz Biotechnology, Santa Cruz, CA) for 2 hours at room temperature. $\beta$-actin receptor antiserum was used for internal control (1:3000 dilution in TBS with 5\% nonfat dry milk and $0.1 \%$ Tween 20; Santa Cruz Biotechnology). Blots were washed and incubated with donkey anti-goat IgG-HRP secondary antibody (1:3000 dilution; Santa Cruz Biotechnology) for 1 hour at room temperature. Immunoreactivity was visualized with an enhanced chemiluminescence Western blotting detection kit (Amersham ECL ${ }^{\text {TM }}$ GST Western Blotting Detection Kit, GE Healthcare, Little Chalfont, UK). Quantitative assessment of band densities was performed by scanning densitometry.

\section{Statistical analyses}

Data are expressed as mean \pm standard error of the mean. Statistical testing was directed to detect overall treatment effects. An unpaired $t$-test was used to compare differences in bodyweight, plasma sample and hemodynamic data, and specific $\beta_{1}$ - and $\beta_{2}$-AR gene and protein expression between the control and high-fat-fed animals.

\section{Results \\ Phenotype of Ossabaw swine}

Chronic high-fat feeding caused many common features of the metabolic syndrome in Ossabaw swine: animals were obese, hyperinsulinemic, dyslipidemic, hypercholestrolemic, and hypertensive (Figure 1 and Table 1). In contrast, control (normal-fed) animals were lean, normotensive, normoglycemic, and had normal lipid profiles.

\section{Hemodynamic parameters}

A high-fat diet of 50 weeks induced many common features of the prediabetic metabolic syndrome. Systolic, diastolic, and mean arterial blood pressures and heart rate were significantly elevated in high-fat-fed Ossabaw swine, compared with their lean controls (Figure 1).

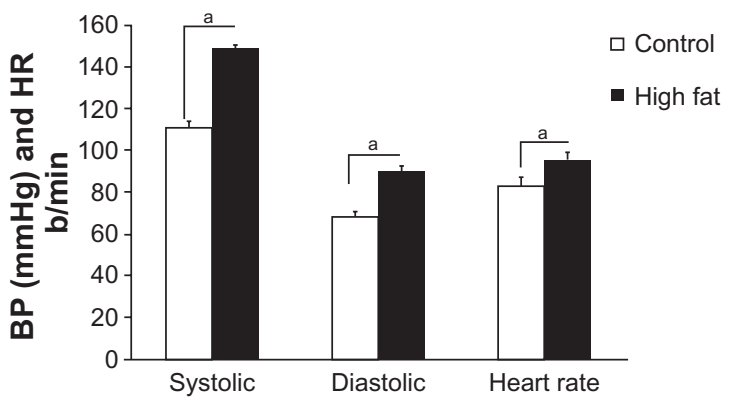

Figure I Systolic BP, diastolic BP, and heart rate from lean and chronic high-fat-diet Ossabaw swine. Systolic and diastolic BPs and heart rate were significantly elevated in the metabolic syndrome group.

Note: ${ }^{a} P<0.05$ versus control.

Abbreviations: BP, blood pressure; HR, heart rate. 
Table I Chronic high-fat feeding significantly increased fasting blood glucose, fasting insulin level, total cholesterol, and triglyceride levels

\begin{tabular}{lcc}
\hline & $\begin{array}{l}\text { Control group } \\
(\mathbf{n}=\mathbf{7})\end{array}$ & $\begin{array}{c}\text { High-fat-diet } \\
\text { group }(\mathbf{n}=\mathbf{9})\end{array}$ \\
\hline Fasting blood glucose $(\mathrm{mg} / \mathrm{dL})$ & $79 \pm 3$ & $106 \pm 9^{\mathrm{a}}$ \\
Fasting insulin level $(\mu \mathrm{U} / \mathrm{mL})$ & $4.8 \pm 1.6$ & $12.1 \pm 4.6^{\mathrm{a}}$ \\
Total cholesterol level $(\mathrm{mg} / \mathrm{dL})$ & $57.0 \pm 5.5$ & $165.6 \pm 8.3^{\mathrm{a}}$ \\
Total triglyceride level $(\mathrm{mg} / \mathrm{dL})$ & $24.7 \pm 3.2$ & $49.6 \pm 2.9^{\mathrm{a}}$ \\
\hline
\end{tabular}

Note: ${ }^{a}<<0.05$ versus control.

\section{mRNA and protein expression of cardiac $\beta_{1}$ - and $\beta_{2}$-ARs in control and chronically high-fat-fed Ossabaw swine}

The quality of total RNA was determined by using distinct $18 \mathrm{~S}$ and 28S ribosomal RNA fragments in the electropherogram. All samples used for analysis were of the same quality and quantity demonstrated in microfluidic-based LabChip sample wells. However, real-time PCR revealed no significant alterations in ventricular $\beta_{1}$ - and $\beta_{2}$-AR mRNA expression in high-fat-fed Ossabaw swine compared with their controls (Figure 2). Pro260 chip-automated gel electrophoresis was used for determining protein quality and quantity (Figure 3 ). Western blot analysis demonstrated a significant decrease in ventricular $\beta_{1}$ - and $\beta_{2}$-AR protein expression (19.86\% and $22.6 \%$, respectively) (Figure 4 ).
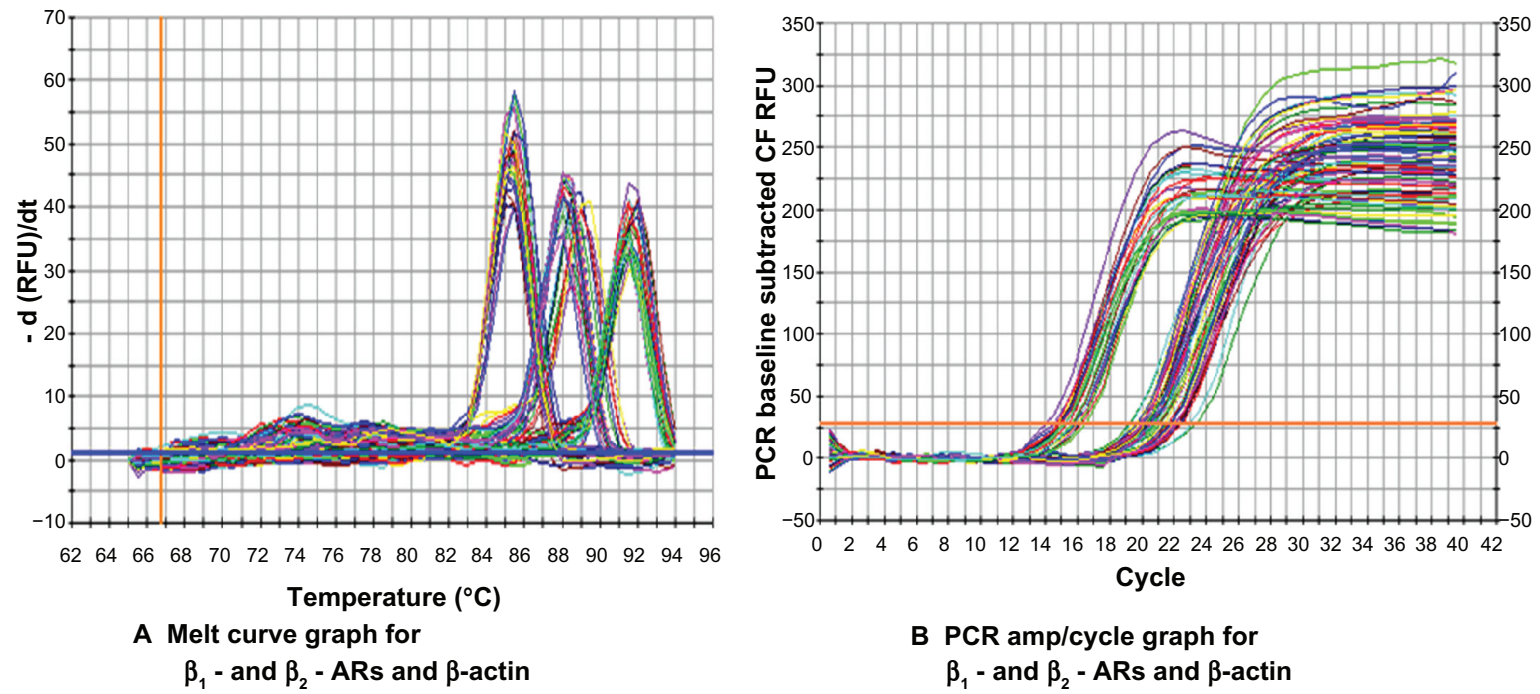

B PCR amp/cycle graph for $\beta_{1}$ - and $\beta_{2}$ - ARs and $\beta$-actin

$\Delta \Delta \mathrm{C}_{\mathrm{T}}=\left(\mathrm{Ct}_{\beta-\mathrm{ARs}}-\mathrm{Ct}_{{ }_{\mathrm{BA}}}\right)-\left(\mathrm{Ct}_{\beta-\mathrm{ARs}}-\mathrm{Ct}_{{ }_{\mathrm{BA}}}\right)$ control

Mean fold change in $\beta_{1}$ - and $\beta_{2}$ - ARs in left ventricle

$2^{-\Delta \Delta c_{t}}=1.1 \pm 0.5$ and $1.4 \pm 0.4$, respectively

Figure 2 Using real-time PCR, no significant changes in mRNA of $\beta_{1}$ - and $\beta_{2}$-ARs were detected in left ventricle obtained from high-fat-fed Ossabaw swine when compared with controls. (A) Melt curve graph for SYBR ${ }^{\circledR} \beta_{1}$ - and $\beta_{2}$-ARs and $\beta$-actin. (B) PCR amp/cycle graph for $\beta_{1}$ - and $\beta_{2}$-ARs and $\beta$-actin.

Abbreviations: CF, curve fit; AR, adrenoceptor; PCR, polymerase chain reaction; RFU, relative fluorescence units; $C T$, mean cycle threshold value. 

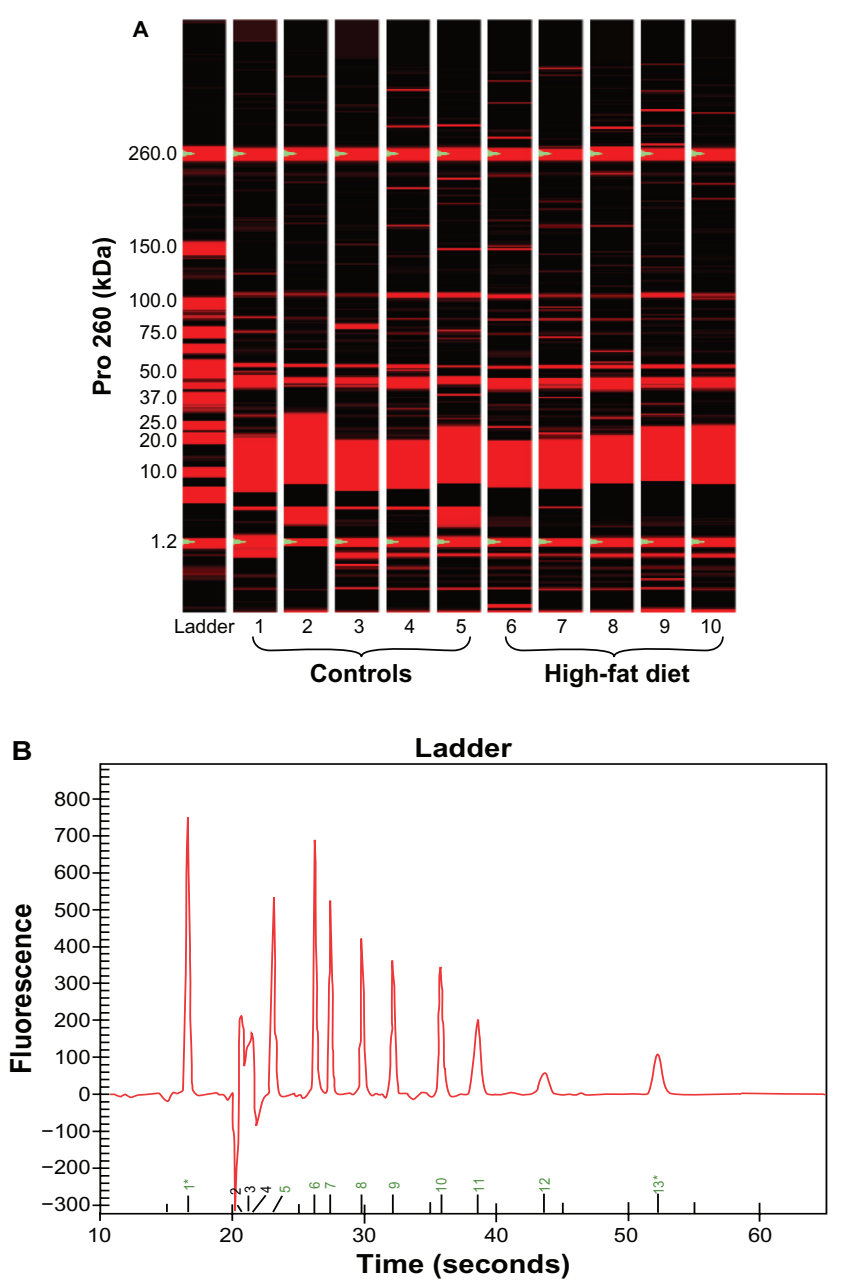

C

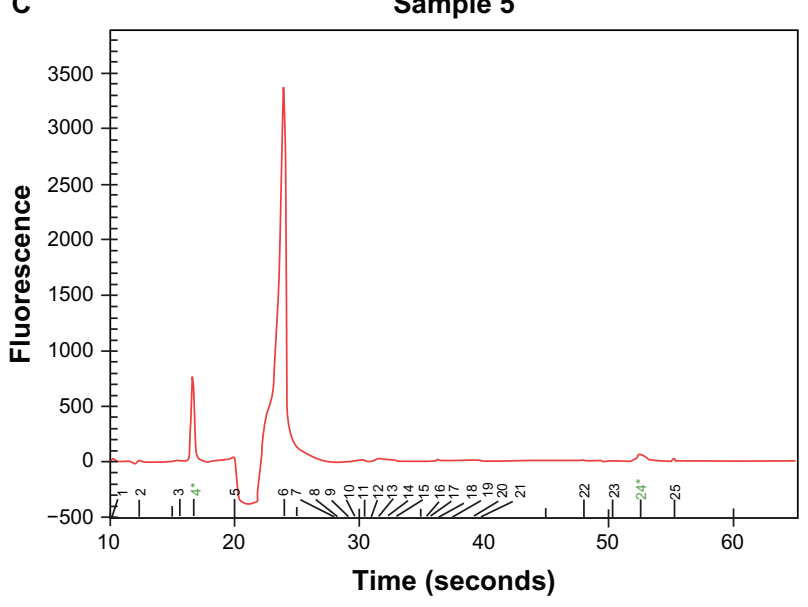

D

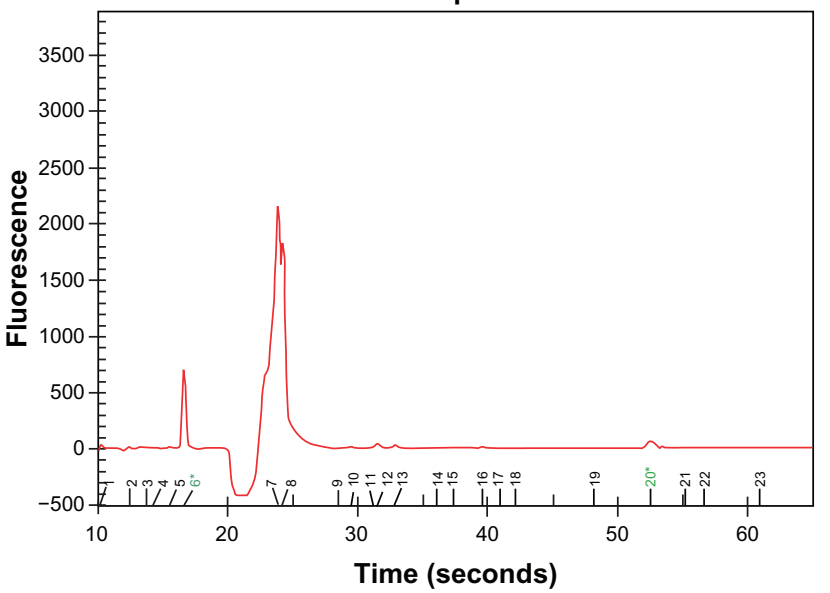

Figure 3 Protein gel electrophoresis (chip). (A) Pro260 chip automated gel electrophoresis. Five controls and five high-fat-diet left ventricle protein gel electrophoresis obtained from Ossabaw swine heart. Basically, $4 \mu \mathrm{L}$ of denatured protein for each sample was loaded into a Pro260 Experion chip (Bio-Rad). (B) Experion Pro260 Ladder electropherogram. The Pro260 ladder contains nine proteins ranging from 10-260 kDa as well as I.2 kDa lower marker. (C and D) Sample electropherograms obtained from control (C) and high-fat-fed (D) left ventricle protein extractions. Left ventricles were homogenized in radio immunoprecipitation assay lysis buffer (which included phenylmethylsulfonyl fluoride and $\mathrm{Na}$ orthovanadate solutions as well as protease inhibitor cocktail). The homogenates were centrifuged at 45,000 rpm for 30 minutes at $4^{\circ} \mathrm{C}$. The supernatants were collected and used for analysis.

imbalances..$^{8,17,18}$ These cardiovascular risk clusters could directly attenuate main cardiovascular function.

Increased sympathetic system activity could cause downregulation of cardiac $\beta$-ARs and could change their secondary and tertiary structures. A persistent hypercatecholaminergic state, which is seen in high cardiometabolic risk subjects, triggers reversible or irreversible protein modifications in cell surface receptors. Both $\beta_{1}$ and $\beta_{2}$ subtypes have been shown to functionally coexist in the human heart. ${ }^{13-16}$ The hazardous effects of elevated catecholamine levels are found to be mediated primarily by $\beta_{1}$-ARs contrary to $\beta_{2}$-ARs stimulation, which may be adaptive in some cases. ${ }^{13,15,16} \beta_{1}$ - and $\beta_{2}$-ARs each couple to $G_{s}$; however, a growing body of recent evidence suggests that $\beta_{2}$-ARs also couple to inhibitory protein $\mathrm{G}_{\mathrm{i}}{ }^{10,12}$ In spite of these differences, the author and colleagues have previously demonstrated that both $\beta_{1}$ - and $\beta_{2}$-AR expression and $\beta_{1}$ - and $\beta_{2}$-AR-mediated inotropic and chronotropic responses were decreased in chronic diabetic hearts. ${ }^{13-16}$ There are a number of explanations for decreased $\beta$-AR expression in metabolic syndrome. Systemic hemodynamic alterations, key protein modifications, and intrinsic functional changes are major factors in attenuating $\beta$-AR-dependent cardiac inotropic and chronotropic responses.

This study found that chronic high-fat feeding resulted in decreased ventricular $\beta_{1}$ - and $\beta_{2}$-AR protein expression, as expected. Real-time PCR revealed no significant alterations in ventricular $\beta_{1}$ - and $\beta_{2}$-AR mRNA. These data directly demonstrate that downregulation of ventricular $\beta_{1}$ - and $\beta_{2}$-ARs is possibly related to constant sympathetic system 

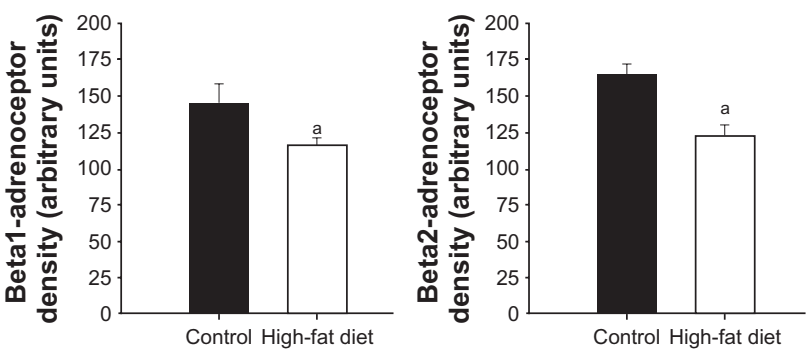

Figure 4 Western blot analysis of $\beta_{1}$ - and $\beta_{2}$-ARs obtained from control and highfat-fed Ossabaw swine left ventricles. Western blot analyses revealed a significant decrease in ventricular $\beta_{1}$ - and $\beta_{2}$-ARs: $19.86 \%$ and $22.6 \%$, respectively. Signal intensities were normalized to concomitant $\beta$-actin.

Note: ${ }^{a} P<0.05$ versus control.

Abbreviation: AR, adrenoceptor.

stimulation. Increased sympathetic system activity stimulates $\beta$-ARs and elevates intracellular cAMP, thereby activating PKA and/or CaMKII. ${ }^{10}$ Recent evidence demonstrates that constant $\beta$-ARs stimulation switches the signaling pathway from PKA to CaMKII predominance in more chronic stages. ${ }^{12}$ Activation of the CaMKII pathway instead of PKA as well as PKA activity and underlying mechanisms were not determined; further experimentation is necessary.

\section{Conclusion}

This is the first report in a novel large animal model where induction of metabolic syndrome is accompanied by a significant reduction in cardiac $\beta_{1}$ - and $\beta_{2}-\mathrm{AR}$ protein expression that could contribute to impaired cardiac function.

\section{Acknowledgments}

The author would like to thank Ridvan and Binnaz Ege (founder of Ufuk University School of Medicine) for their support, and also thanks Michael Sturek, Johnathan D Tune, and Mouhamad Alloosh (Department of Cellular and Integrative Physiology, Indiana University School of Medicine, Indianapolis, IN) for their contributions. This work was supported by grants of the National Institutes of Health: HL67804 JD Tune; and HL062552 and RR013223 M Sturek. The author would also like to thank Yang Gao for his technical assistance and contribution. All contributors gave their permission for this manuscript to be published independently from their own work.

\section{Author's contributions}

$\mathrm{U}$ Deniz Dincer MD, PhD designed the experiment and analyzed the data discussed in this paper, and wrote the manuscript. This work was completed at the Indiana University School of
Medicine, Department of Cellular and Integrative Physiology, IUPUI, Indianapolis, IN (Dr JD Tune's laboratory).

\section{Disclosure}

The author reports no conflicts of interest in this work.

\section{References}

1. Steinberger J, Daniels SR. Obesity, insulin resistance, diabetes, and cardiovascular risk in children: an American Heart Association scientific statement from the Atherosclerosis, Hypertension, and Obesity in the Young Committee (Council on Cardiovascular Disease in the Young) and the Diabetes Committee (Council on Nutrition, Physical Activity, and Metabolism). Circulation. 2003;107:1448-1453.

2. Alpert MA. Management of obesity cardiomyopathy. Am J Med Sci. 2001;321:237-241.

3. Alpert MA. Obesity cardiomyopathy: pathophysiology and evolution of the clinical syndrome. Am J Med Sci. 2001;321:225-236.

4. Dyson MC, Alloosh M, Vuchetich JP, Mokelke EA, Sturek M. Components of metabolic syndrome and coronary artery disease in female Ossabaw swine fed excess atherogenic diet. Comp Med. 2006; 56:35-45.

5. Carroll JF, Jones AE, Hester RL, Reinhart GA, Cockrell K, Mizelle HL. Reduced cardiac contractile responsiveness to isoproterenol in obese rabbits. Hypertension. 1997;30:1376-1381.

6. Hall JE, Brands MW, Zappe DH, et al. Hemodynamic and renal responses to chronic hyperinsulinemia in obese, insulin-resistant dogs. Hypertension. 1995;25:994-1002.

7. Hall JE, Brands MW, Zappe DH, Alonso GM. Insulin resistance, hyperinsulinemia, and hypertension: causes, consequences, or merely correlations? Proc Soc Exp Biol Med. 1995;208:317-329.

8. Dincer UD, Araiza AG, Knudson JD, Molina PE, Tune JD. Sensitization of coronary alpha-adrenoceptor vasoconstriction in the prediabetic metabolic syndrome. Microcirculation. 2006;13:587-595.

9. Grassi G, Dell'Oro R, Quarti-Trevano F, et al. Neuroadrenergic and reflex abnormalities in patients with metabolic syndrome. Diabetologia. 2005;48:1359-1365.

10. Lefkowitz RJ, Rockman HA, Koch WJ. Catecholamines, cardiac beta-adrenergic receptors, and heart failure. Circulation. 2000;101: 1634-1637.

11. Wehrens XH, Lehnart SE, Reiken S, Vest JA, Wronska A, Marks AR. Ryanodine receptor/calcium release channel PKA phosphorylation: a critical mediator of heart failure progression. Proc Natl Acad Sci US A. 2006;103:511-518.

12. Xiao RP, Zhu W, Zheng M, et al. Subtype-specific alpha1- and betaadrenoceptor signaling in the heart. Trends Pharmacol Sci. 2006; 27:330-337.

13. Dincer UD, Onay A, Ari N, Ozcelikay AT, Altan VM. The effects of diabetes on beta-adrenoceptor mediated responsiveness of human and rat atria. Diabetes Res Clin Pract. 1998;40:113-122.

14. Dincer UD, Ozcelikay AT, Yilmaz ED. The effects of chronic L-name and L-arginine administration on beta-adrenergic responsiveness of STZ-diabetic rat atria. Pharmacol Res. 2000;41:565-570.

15. Dincer UD, Bidasee KR, Guner S, Tay A, Ozcelikay AT, Altan VM. The effect of diabetes on expression of beta1-, beta2-, and beta3adrenoreceptors in rat hearts. Diabetes. 2001;50:455-461.

16. Dincer UD, Guner S, Tay A, et al. Decreased expression of beta1- and beta2-adrenoceptors in human diabetic atrial appendage. Cardiovasc Diabetol. 2003;2:6

17. Dincer UD, Araiza A, Knudson JD, Shao CH, Bidasee KR, Tune JD. Dysfunction of cardiac ryanodine receptors in the metabolic syndrome. J Mol Cell Cardiol. 2006;41:108-114. 
18. Setty S, Sun W, Tune JD. Coronary blood flow regulation in the prediabetic metabolic syndrome. Basic Res Cardiol. 2003;98 416-423.
19. Livak KJ, Schmittgen TD. Analysis of relative gene expression data using real-time quantitative PCR and the 2(-Delta Delta C(T)) method. Methods. 2001;25:402-408.

\section{Publish your work in this journal}

The International Journal of General Medicine is an international, peer-reviewed open-access journal that focuses on general and internal medicine, pathogenesis, epidemiology, diagnosis, monitoring and treatment protocols. The journal is characterized by the rapid reporting of reviews, original research and clinical studies across all disease areas.
A key focus is the elucidation of disease processes and management protocols resulting in improved outcomes for the patient.The manuscript management system is completely online and includes a very quick and fair peer-review system. Visit http://www.dovepress.com/ testimonials.php to read real quotes from published authors.

Submit your manuscript here: http://www.dovepress.com/international-journal-of-general-medicine-journal 